\title{
ETHICAL CHALLENGES IN DIFFERENT INTERPRETING SETTINGS
}

\author{
Sylvia Kalina \\ Fachhochschule Koeln \\ sylvia.kalina@fh-koeln.de
}

\begin{abstract}
This article addresses professional ethics and codes of conduct for interpreters who work in different interpreter-mediated settings and therefore have to adapt to a great range of different circumstances and expectations. Codes of ethics provide guidelines but some of them remain very general when it comes to specific questions such as that of impartiality and of the role an interpreter assumes in any given setting. It will be argued that although some of the more general rules apply across the board, those that are more specific need special attention as they have to be applied differently from one setting to the next. It therefore pleads for a training environment in which setting-specific deontologies can be trained, as well as for more information to the general public who must understand that well-trained interpreters in all fields are essential for the services to be rendered in bi- or multilingual intercultural encounters of all types.
\end{abstract}

\section{Resumen}

Este artículo aborda la ética profesional y los códigos deontológicos que rigen el trabajo del intérprete en diversos entornos que requieren su intervención, por lo que ha de adaptarse a una amplia gama de circunstancias y expectativas. Los códigos éticos ofrecen las líneas directrices pero algunos siguen siendo muy generales a la hora de tratar cuestiones específicas como la imparcialidad o el papel que el intérprete adopta en cada entorno. Se aduce que aunque algunas de las reglas más generales se aplican por igual, las que son más específicas necesitan una atención especial pues han de ser aplicadas de manera individualizada en los respectivos entornos. El artículo defiende un espacio formativo en el que se enseñen las deontologías específicas y se ofrezca más información al público amplio que debe comprender que los intérpretes bien preparados son esenciales para que se puedan prestar servicios en encuentros culturales bilingües y multilingües. 
Keywords: Interpreting ethics. Translational norms. Interpreting settings. Role. Impartiality.

Palabras clave: Ética de la interpretación. Normas de traducción. Entornos de la comunicación. Papel. Imparcialidad.

Manuscript received on March 1, 2013 and accepted for publication on January 19, 2014. 


\section{Professional ethics and codes of conduct}

\subsection{Ethics and norms as guiding principles for professional conduct}

\subsubsection{General ethical principles}

Ethics can be defined in very general terms as the respect of certain values, to be achieved by adhering to rules and principles that have developed within a society or were laid down by a group for its members. It is a concept which refers to human behaviour and human action. Ethical considerations may precede and cause human action; they may also be applied as a yardstick against which behaviour is measured. Therefore, ethics may refer either to the attitude by which an individual's action is guided or to the effect that such action has on others.

The law of ancient Buddhist and Hinduist philosophies, which has been termed the Golden Rule", says "Do unto others as you would have them do unto you", and the same idea is reflected in the Christian Bible (Luke 6:31) and in other religions. Philosophical approaches to ethics find their expression in Kant's categorical imperative which stipulates: "act only according to that maxim whereby you can, at the same time, will that it should become a universal law without contradiction" (translation: Ellington 1993: 30). By extension, the Golden Rule and Kant's categorical imperative describe action which should be avoided: "do not impose on others what you do not wish for yourself". From a philosophical and research-oriented point of view, "ethics is the enquiry into what is good, $[\ldots]$ what is valuable, or, into what is really important" (Wittgenstein 1929: 1).

Hebenstreit emphasises the moral justification of ethical decisions and refers to a model of ethical decision-making designed by an American sign language interpreter and interpreter trainer, Jack Hoza:

Ethical decision defined: A decision that is made between two or more possible right, but competing, solutions that arise in a situation in which the person is torn between two or more conflicting ethical principles or guidelines.

1.www.ehow.com/about_6337031_ethics-golden-rule.html, accessed 2013-02-06. 
An ethical decision, then, involves determining which solution is "most right" within a particular context. (Hoza 2003: 10, as quoted by Hebenstreit 2010: 286)

Hebenstreit regards the individual as responsible for a decision that pertains to social reality in general and is thus a social and ethical concern (2010: 283ff). The balance between freedom and responsibility is also at the centre of Prunčs approach to translation ethics. For Prunč, translation culture is defined as "the set of norms, conventions, values and behavioural patterns used by all the partners involved in translation processes in a certain culture" (Prunč 2012: 2). Referring to settings where power is distributed asymmetrically between the parties to a discourse, Prunč acknowledges the need for codes of ethics that are adapted to specific settings; at the same time, he warns that such codes cannot cover all the moral and ethical challenges that an individual interpreter may be faced with (Prunč 2007: 329). For a more translation-specific approach, e.g. by Chesterman (2001), see 1.2.

\subsubsection{Ethics and norms of professional conduct}

Members of a profession usually develop a deontology, i.e. guidelines of professional ethics; the principles or rules that make up such guidelines are enshrined in codes of ethical and/or professional conduct and are established, in general, by professional associations. All members of an association are obliged to abide by these rules. In some settings, such as court and medical interpreting, codes of practice are established by providers, i.e. the authorities that are responsible for the functioning of the service and/or for the accreditation of interpreters; this is the case in the U.S. and some other countries. The codes provide guidance as to professional behaviour and sometimes give an orientation on conduct for situations in which conflicting interests or objectives make it difficult to determine which type of action or conduct is most appropriate or justified. If there is more than one 'right' decision, a set of ethical guidelines will, in the ideal case, provide criteria that enable the individual to adopt one of several possible solutions. An ethical solution to a problem is one for which the individual concerned can assume full responsibility.

The ethical principles agreed upon by the members of a profession focus on professional conduct towards each other and towards the outside world. Professionalism must be based, among other things, on professional ethics and general ethical behaviour.

Professionalism could be defined as gaining and maintaining credibility as an occupational group towards the public and those served (the general public, patients or customers, business clients) whilst ethics would be more 
closely related to how the professional group connects with and is bound by the wider community and its current moral values, obviously dictated by socio-political and cultural paradigms. (Rudvin 2007: 50)

To enable the general public and clients to distinguish between a translator's ethical conduct and unethical or unprofessional action, codes of conduct and ethics serve to make translators' and interpreters' behaviour transparent (cf. Rudvin 2007: 52).

Tenets of ethical behaviour are often laid down in the form of norms. These refer to specific fields of action and are developed in daily practical routine. When applied to the rendering of services, such norms reflect admissible options of behaviour on which there is general agreement among those who offer the type of service in question. When laid down in (international) agreements covering a certain professional activity, such norms may also serve as a basis for quality assurance. Often, norms take the form of rather pragmatic rules that are applied flexibly according to situation and actors concerned. The rule of confidentiality, for example, may be overridden by the interest of the client in disclosure, or by law (cf. AUSIT Code of Ethics and Code of Conduct 2.4, and CHIA Standards for Healthcare Interpreters, which addresses also potential conflicts regarding confidentiality in healthcare interpreting). Norms can give us some guidance as to what we should do, what is adequate or inadequate in a particular situation and how we should solve numerous problems that may arise in our professional activity.

\subsection{Ethics and professional norms in translation}

In line with the above and for the purpose of this article, ethical rules refer to what is valuable or right behaviour in life as a whole; as such, they are applicable to professional conduct in the field of translation. Norms are then defined as referring to ways of actual behaviour and transfer-related solutions; it is the professional community of translators/interpreters that agrees on their appropriateness. They are, as Toury points out, operational insofar as they govern the actual translation or interpreting process/product and the decisions to be made on the spot (1980: 53ff). Toury defines norms in translation as "values or ideas shared by a certain community as to what is right and wrong, adequate and inadequate" and "a category for descriptive analysis of translation phenomena" (Toury 1980: 57).

It may be assumed that a number of guiding principles are shared by the two sub-disciplines of translation studies, i.e. research into written translation and oral interpreting. For translation ethics, Hebenstreit (2010) chooses Chesterman's approach as a starting point. Chesterman (2001) distinguishes 
four ethics: ethics of representation, ethics of service, ethics of communication and norm-based ethics. According to this approach, the following values and virtues make for excellence: commitment, fairness, truthfulness, trustworthiness, empathy, courage, determination (for a more detailed discussion of these virtues and values see Hebenstreit 2010: 290). Referring again to Hoza (2003) and his view of codes of professional conduct as action guides, Hebenstreit (2010: 293) argues that the rules of such codes serve as an important instrument for solving moral problems that may arise in a professional context; however, such rules can explain only what exists in terms of translational standards or values and they are a function of the model of translation on which they are based. For Hebenstreit, the implementation of translation ethics depends on the translator's willingness to assume responsibility by putting the act of translating in context, taking intertextual, interpersonal and social factors into account. The translator is a partner in communication with his/her own intentions and expectations (Hebenstreit 2010: 282).

For Marzocchi, norms explain diverse ways of determining translation: historical, social, or cultural. Norms are "regularities of translational behaviour", and departure from a norm will result in some form of social sanction (2005: 88). If that is the case, a norm is not descriptive but prescriptive, i.e. it must be assumed to be binding. In an approach that combines the internal translator-related perspective with that of the outside world, Chesterman (1993) distinguishes two types of norms: professional norms (role, relationship between source text and target text, as defined by competent professional translators, and their methods and strategies) and expectancy norms (established by the expectations of the client). Professional norms are subordinate to expectancy norms. One may assume that this distinction also applies to interpreting. Schäffner defines norms in translation studies as knowledge of what is regarded as correct and appropriate behaviour. That behaviour is developed through socialisation and is shared by members of a given community (1999: 1). In conference interpreting, this community is made up of conference organizers, participants, speakers, interpreters and professional associations such as AIIC that have their own Codes of Ethics.

In Shlesinger's attempt to build a bridge between written translation and oral interpreting, norms are generally defined as "the manifestation of shared values or ideas in recurrent situations of the same type" (1989: 111f). Shlesinger sees a methodological problem when norms are defined on the basis of individual interpreter behaviour (individual versus across-the-board phenomena); it lies in the lack of comprehensive and representative corpora that would be appropriate for analysis (1989: 113). It is not always easy to 
distinguish between what constitutes a norm and is therefore part of the expertise of the profession and what is an ethical principle which helps the interpreter deal with the outside world and respecting the interests of all parties involved. Norms and ethical principles affect interpreting quality when quality is understood to be more than the interpreting product as such.

\section{The role of ethics in interpreting}

\subsection{Distinguishing types of interpreting in various settings}

Interpreting today falls into a number of subtypes such as conference, business, legal and healthcare interpreting, interpreting in refugee camps, refugee determining situations, interpreting in zones of war or crisis and others (cf. Gentile 2012: 158). There is agreement that general ethical principles such as discretion, professional secrecy, careful handling of documents received, and, with a view to interpreting quality, accuracy, apply to virtually all interpreting situations and settings; this is reflected in many codes drawn up for different settings (cf. AUSIT 2012, CHIA 2002, ITIA 2009, NAATI 2013, RID 2005, and many others). Continuing professional development has also become one of these essentials.

Adherence to ethical principles in the act of interpreting, however, presupposes also the awareness that an interpreted discourse is always dependent on the source text, the setting, context, and the individuals participating in an act of communication. Communication partners must be aware of this. The interpreter is obliged, on the one hand, to respect this dependency, but is also under the obligation to act in the interest of the recipient of the utterance. The interpreter therefore has to be aware of the rights and obligations each participant has in a specific setting, which may vary from one setting to another. It is not always easy to decide which norms interpreters are expected to abide, and whose expectations we are talking about. This holds true for all types of interpreting. Norms have developed 'by doing', i.e. by professional work, by teaching and by observation of colleagues. In the literature, authors like Stenzl (1989) and Shlesinger (1999) have pointed out early how little we have really reflected on the principles by which we are guided. Moreover, when considering rules, norms and expectations, we have to examine for each individual case whether a certain norm is appropriate for a given setting and helps fulfil the function of the service rendered. 


\subsection{Professional ethics in conference interpreting}

Ethics in interpreting was first discussed in the context of conference interpreting, where the concept of 'professional dignity' was developed with the aim of protecting the profession by contributing to the work of professional associations, developing a professional profile, observing what codes existed and refraining from any action prejudicial to the reputation of the profession. Soon after the establishment of AIIC (the International Association of Conference Interpreters) in the 1950s, these principles were enshrined in members' codes of honour and ethical conduct. AIIC's code of ethics specifies rights and obligations of a conference interpreter, as well as a commitment to quality; in Articles 2 to 6 it deals with standards of integrity, professionalism and confidentiality. Members of the association shall be bound by the strictest secrecy and refrain from deriving any personal gain whatsoever from confidential information, not accept any assignment for which they are not qualified, not accept any job or situation which might detract from the dignity of the profession, not accept more than one job for the same period of time, and refrain from any act which might bring the profession into disrepute. Members of the association are expected to afford their colleagues moral assistance and collegiality (which includes team spirit and solidarity) and refrain from any utterance or action prejudicial to the interests of the association and its members. Other commitments made refer to the protection of the reputation of the profession and the association, working conditions and prerequisites for quality (see AIIC Code of Professional Ethics).

In interpreting, ethical principles apply not only to the act of interpreting, i.e. the production of output, but also to the interpreter's general behaviour prior to, during, and after an event (cf. e.g. Schweda Nicholson 1994). Recently, the the Directorate General for Interpretation of the European Commission (SCIC) has provided its interpreters with a set of ethical guidelines which comprise professional integrity, loyalty towards the institution (and, as a novelty, observance of social media guidelines), respect and confidentiality. The guidelines also mention recommended behaviour in cases of harassment, as well as team spirit, booth manners etc. This internal document provides a set of guidelines for work with the institutions of the European Union; it would doubtlessly be desirable to have other, no less specific guidelines for other settings and contexts. 


\subsection{Research on norms in conference interpreting}

Whereas the aforementioned principles serve as guidelines for professional behaviour in general, norms, as suggested above, refer rather to actual conduct and transfer decisions that determine the quality of interpreter output. In the United States, the standards of what conference interpreters are expected to do and not to do were initially defined by those hiring them, i.e. clients, or by large services that started to build up their own quality assurance systems. In the early phases, these standards included invisibility, even self-denial (cf. Angelelli 2004), but also empathy with speakers from other cultures, acceptance of roles and styles of individual speakers, completeness, knowledge of subject matter, intuition and neutrality. These principles continue to be part and parcel of ethics in conference interpreting. Conference interpreters who work in other settings must be aware of this and should acquaint themselves with the ethical rules of these settings.

In her article on norms in conference interpreting, Duflou focuses on the purpose of norms and defines them as "guidelines for behaviour that help an interpreter to choose from the range of possible renderings of a speaker's utterance one that is considered right by the interpreting community to which she belongs" (2007: 90). A certain type of behaviour is regarded as a norm if the conditions of regularity, negative sanctions, and belief are met (Duflou 2007). However, the norms that professional interpreters regard as such are not necessarily identical with those of users, as was revealed in Bühler's questionnaire and interpreters' response (Bühler 1986, Seleskovitch 1986).

Shlesinger distinguishes norm-driven strategy use from cognitive constraints, and such strategic action means heeding an obligation or avoiding a prohibition, such as "sanctions on a very uneven delivery marked by prolonged silences, even if the output per se is complete" (1999: 73). Authors agree that norms may be determined either by interpreters themselves or by their clients, listeners or organisers; what these groups regard as a norm is by no means the same thing. It is therefore essential that all groups should be actively involved when it comes to the definition of international standards.

In her discussion of quality, Garzone defines norms as a "heuristic instrument to account for variability in quality criteria and standards, as perceived and (above all) as practised by interpreters and users. This variability is a function of the situation and of the social (sub-)groups involved in each interpretation event" (2002: 110). The interrelationship between norms and quality becomes apparent when she goes on to define norms as

internalised behavioural constraints which govern interpreters' choices in relation to the different contexts where they are called upon to operate, the 
aim being to meet quality standards, which in turn are strictly connected with the sociocultural context and are, therefore, norm-based (Garzone 2002: 110).

Based on the foregoing, I shall assume that norms reflect how we define interpreting quality. I will regard norms as those patterns of interpreting behaviour that are adopted by professional interpreters on the basis of their ethical approach to the profession and the procedural knowledge they share among themselves and with their informed clients.

We know little as to what happens when norms are violated. Evidence of possible consequences is anecdotal, as e.g. when occurring in a chairperson's or delegate's remarks, or the TV moderator's reactions, or an occasional press report. The question is whose reactions are more relevant, those of the users, or colleagues, or organizers. Empirical studies on such phenomena in the field of conference interpreting are still far too few.

\subsection{Professional ethics in asymmetrical interpreting settings}

Interpreting in asymmetrical settings is mostly referred to as 'community interpreting'. It usually takes place between an expert representing the powerful side (the state, local authority) and a client (e.g. tourist, migrant), with different levels of education and often widely differing cultural backgrounds. This imbalance has a bearing on the register used by the primary participants, and the interpreter needs a high degree of intercultural sensitivity and empathy to take the different perspectives, registers and interests into account (cf. Hale 2007: 31f). Such asymmetrical settings comprise the majority of legal settings (court, police) where the expert side is represented by judges, lawyers, police officers, etc., and the client is a suspect, defendant or a victim or witness. In healthcare settings the interaction is generally between a medical expert (doctor) and a patient (for a detailed discussion see Pöchhacker \& Shlesinger 2007). In asylum hearings where an officer interviews an applicant, this imbalance is particularly blatant.

In the above-mentioned settings, the professional profile of interpreting appears to be more multifaceted than in conference interpreting. Especially in the United States, interpreters working in healthcare or legal settings have adopted recommendations that include ethical behaviour. Institutions in some countries have set up guidelines or even certification procedures, thus contributing to the professionalisation of this type of interpreting. Where this is not the case, many members of migrant communities regard the knowledge of the host language and their own as sufficient to offer their services as an interpreter. These people are rarely aware of codes of ethics even where 
these exist; interpreting quality and the conduct of such individuals are often beyond the control of anyone else, especially in the case of less widely spoken languages. Yet abiding by ethical guidelines is of crucial importance in such settings. Interpreters have to assume responsibility for their actions and decisions, which is sometimes difficult, e.g. when a client regards an interpreter as his or her ally just because s/he belongs to the same ethnic group (cf. Hale 2008: 102f; Andres 2009: 132f). Moreover, interpreters in such settings obtain information that is often very personal and not intended for them, and its handling requires a high degree of confidentiality (Gentile et al. 1996: 59). The Code of Professional Responsibility for Federal Court Interpreters (1993) of the United States, which has since then been transposed into several U.S. state codes, stipulates that interpreter behaviour should be "unobtrusive and unbiased, never revealing through word or gesture their own impression or opinion of the proceedings" (Hewitt 1995: 79, cf. also Apple et al. 1997: Appendix 19).

Quality standards in community settings are often intertwined with ethical prerequisites, as the following list of quality components contained in most codes of ethics (see 2.1) illustrates: the interpreter's overall role, competence and required skills, impartiality, completeness and accuracy, conflicts of interest and grounds for disqualification, confidentiality, and continuing professional development (cf. Schweda Nicholson 1994: 82). Ko (2006: 51) and Schweda Nicholson make another important point: "Anything that could interfere with a true and faithful rendition requires that she [the interpreter] ask to be excused from the case" (Schweda Nicholson 1994: 91); Ko illustrates the difficult decision between two conflicting interests:

On the one hand, it is unethical and unprofessional for an interpreter or translator to withdraw from an assignment after he/she has accepted it. [...] On the other hand, it is also unethical and unprofessional for an interpreter or translator to continue an assignment when he/she is unable to interpret or translate accurately. (Ko 2006: 51)

Conflicts of interests are also likely to arise when a representative of one side acts as an interpreter, a circumstance which always weakens the position of the other side and violates the principle of impartiality.

It is important to understand that ethical conduct of interpreters in settings with an asymmetrical power relationship is necessarily different from the principles by which conference interpreters, who usually work in more symmetrical settings, abide. Therefore, it appears necessary to draft distinct codes of ethics that will share some common principles but differ in other aspects. One case in point is the requirement of literalness ('verbatim requirement') 
of the interpreted version of an utterance. Here, expectations differ between different settings but also between legal cultures. In the U.S., courts expect the interpreter to be extremely literal, reflecting also the ways in which an utterance may be expressed, as the following quote illustrates:

Interpreters are expected to convey every element of meaning of the source-language message, without adding, omitting, editing, simplifying, or embellishing. In other words, they must maintain the tone and register of the original message, even if it is inappropriate, offensive, or unintelligible. (Mikkelson 1998: 1)

In many European countries, by contrast, expectations are different from this view. In some countries, e.g. in Austria, the court interpreter is regarded as an expert for a foreign language (Kadric 2001: 125) which means that, in addition to the linguistic transfer, the interpreter gives explanations when the cultural knowledge of one party is not sufficient to understand the other party (Kadric 2001: 55).

Obviously, the setting, i.e. context, participants and conditions, influences the type of norms defined, as Shlesinger points out (1989: 111f); from this it follows that different settings will require different norms and ethical principles (cf. Gentile 2012: 158). As the European Union is about to bring about more harmonization in different sectors of its societies, it would be reasonable to attempt to find common rules that apply to these sectors. ImPLI (Improving Police and Legal Interpreting), a project co-funded by the European Commission (DG Justice), has, among other things, tried to pave the way for Europe-wide ethical guidelines for interpreting in police settings.

The standards for professional interpreting include, apart from confidentiality as mentioned in the Directive, impartiality, trustworthiness, reliability, and discretion. In addition, ethical principles include that interpreters should accept only work assignments for which they are qualified, that they should decline work if it involves unprofessional behaviour or disrespect of ethical principles, and that they should be extraordinarily conscientious in the handling of documents and files obtained. (ImPLI Final Report 2012: 39)

Another attempt at introducing common standards at international level is the work (in progress) by Technical Committee 37 of the International Standards Organisation (ISO). It addresses community interpreting in general and is intended to be used for quality assurance and certification purposes. 


\section{Impartiality and role definition as ethical challenges}

\subsection{Impartiality}

The view that impartiality is not a strict rule applicable to all interpreting is supported by a closer look at some of the tenets contained in codes of ethics for interpreters. Impartiality is not listed in all codes of ethics, although it is absolutely essential for conference interpreting. This setting is largely influenced by Western culture and traditions, where conference interpreting was first practiced and taught. Here, the interpreter's task is seen as giving

an accurate account of the interlocutors' utterances, and the interpreter does not serve interests of either party. Indeed, this is the cardinal tenet of virtually all interpreter codes of ethics. (Rudvin 2007: 62)

Although it is regarded as one of the fundamental principles of all conference interpreting, impartiality is not specifically mentioned in the AIIC code, whereas the code of professional conduct of ITI (Institute of Translation and Interpreting, based in the UK) is more specific, requiring members to "interpret impartially between the various parties" (cf. Diriker 2001: 35, see also Diriker 2004 for a detailed analysis of impartiality and objectivity).

In conference settings where interpreters are usually recruited by an event manager, organiser or by interpreter colleagues, it is self-evident that all points of view should be given the same weight, no matter whether the interpreter thinks that they serve the interest of communication or not, and of course even if s/he has an entirely different point of view. If one participating side requests or instructs interpreters to play down critical remarks (e.g. a pharmaceutics manufacturer might request this when users wish to discuss side effects), a professional interpreter will refuse to comply with any such request. Along with many others, Schweda Nicholson (1994: 82) stresses the importance of accuracy and impartiality as two interconnected aspects of conference interpreting. This illustrates the close interrelationship between ethical and quality aspects.

When the setting is asymmetrical and the clients involved are members of a migrant community, the interpreter often has to mediate between different cultures. Such a task may even imply taking sides, and in general the side of the weaker party will be supported. Here, it is difficult to delineate how far an interpreter may go in taking one side without giving up his/her trustworthiness for the other side. And above all, it is difficult for the other side to find out whether an utterance has been faithfully interpreted or the interpreter has adapted it to help the weaker side. Therefore, such side-taking entails risks and should not be regarded as a general interpreting strategy. The 
skills required for this go far beyond linguistic knowledge, and are similar to those of an intercultural expert. But in most cases the interpreter does not have a cultural expert's knowledge. As Niska puts it, "it is not far-fetched to assign the function of cultural mediator to the interpreter. After all, to be able to interpret 'linguistically' the interpreter needs cultural knowledge as well. But his knowledge is not necessarily that of an expert" (1995: 299f). Exactly which intercultural skills are required and where the mediating function of an interpreter has its limits is not always clear. Officers in asylum hearings often have their doubts regarding the impartiality of the interpreter. It often happens that participants in a discourse, especially when they represent a party in a legal case, suspect the interpreter of being biased, be it because $\mathrm{s} /$ he is a member of one of the parties, be it for other reasons. Admittedly, the temptation not to be impartial is great if an interpreter is recruited from one of the contestant groups. However, it must be kept in mind that bias not only results from the act of interpreting. Bias also occurs in monolingual settings as participants' comprehension processes are influenced by their own opinions, previous knowledge and mental model.

In some situations, it may be appropriate for an interpreter to give up his/ her impartiality or neutrality. If, for example, an interpreter is expected to offset inequalities that result from different cultural traditions by drawing the attention of one side to circumstances that have not been communicated by the other, this is called 'advocacy' (cf. Andres 2009: 139). Advocacy for the weaker side may negatively affect other ethical principles such as accuracy and completeness.

Above all, community interpreters need to have the competence to make consistent ethical decisions in the continuum between neutrality and advocacy (Prunč 2012: 8)

Andres (2009: 133) emphasizes the conflicting responsibilities and role expectations especially in the field of community interpreting, where impartiality may not necessarily be a guiding principle and it is the personal responsibility of the interpreter to determine where and when one side needs more than a verbatim rendering. The Code of Professional Conduct of the Registry of Interpreters for the Deaf (RID 2005) does not include impartiality among its main tenets, and sign language interpreters in general do not always regard themselves as impartial.

In settings such as legal interpreting (court and police), impartiality is the overriding principle, although the interpreter is recruited (and paid, however poorly) by the legal or law enforcement authorities. These generally insist on verbatim versions, unaware of the fact that interpreting takes place not 
only between languages (language codes) but between cultures; their verbal as well as nonverbal expressions and discourse patterns may differ widely and often need some explanation or comment in order to be understood by addressees in the target culture. Such additions, comments and explanations are frequently regarded as violations of the requirement of 'literal translation' (legal experts usually use the term 'translation', not 'interpreting'). This view

[...] is a direct result of what is known as the 'conduit' approach, in which the interpreter is perceived as an invisible pipe, with words entering in one language and exiting - completely unmodified - in another language. The law therefore views the interpreter as a mechanical instrument, to be used entirely as the court sees fit. In the contrasting situation, defendants who have no command of the language relate to interpreters as their saviours. Finally they have found somebody with whom they can communicate readily and who represents home. (Morris 1999: 6f)

A defendant, on the other hand, may feel powerless and exposed and therefore expect the interpreter, especially when the latter is a member of the same community, to be on his/her side (cf. Hale 2008: 102f). In such circumstances, impartiality is difficult for the interpreter to maintain.

Interpreters often find themselves in situations that make it very difficult to adhere to this precept. For example, a defendant who can communicate with no one but the interpreter will ask questions about the case and may solicit opinions or advice. Interpreters may feel tempted to explain judicial practices or answer factual questions, especially for defendants who are not represented by counsel, but the standards of professional conduct make it clear that they are strictly forbidden to do so. (Mikkelson 1998:3)

The judicial side, however, expects the interpreter to be absolutely neutral and often tend to suspect interpreters to be on the side of a defendant. This, however, would have serious consequences (cf. Hale 2008: 110). Trust in the interpreter and his/her skills is a crucial condition for successful interpreting.

The expectations that participants in interpreted medical encounters have are again different; here, the medical expert side often expects the interpreter to help overcome cultural barriers to communication with the patient, and impartiality is not something the interpreter strives to maintain, as in general, both sides have similar aims. In community settings (public institutions, social welfare departments, but also schools, etc.), each of the two sides (public authority and client wishing to obtain a service) often expect the interpreter to be on their side. Here, the interpreter sometimes renders a service that goes beyond linguistic mediation and informs a client of whatever the latter might find useful to know. In all settings where power relationship is 
unbalanced, the ethical rule tends to be to help the weaker side obtain their rights or claims (cf. also Andres 2009).

There is also the emotional aspect which should not be ignored. It may happen that an interpreter is, for emotional reasons, unable to start or continue to interpret. This has been reported in the context of the hearings of the South African Truth and Reconciliation Committee (cf. Lotriet 2000), where interpreters were made to interpret for people who had brutally killed their closest relatives, and in connection with other court proceedings when cases involving crimes against humanity are heard.

Impartiality may also be at risk when interpreters are not free-lance but employed and the employer has the right to instruct the interpreter to act in a certain way, e.g. to disclose a piece of information not intended for them. This constitutes a violation of the principle of confidentiality, and as a result of the interpreter's impartiality. The same is true when an overriding moral interest, e.g. to prevent an imminent violent crime, leads an interpreter to disregard the principle of confidentiality. The decision on how to act in such a case is a very personal one, and it may entail a conflict between professional ethics and personal well-being.

\subsection{Roles and conflicts}

The above discussion of an intercultural mediation role of an interpreter raises the question of which roles interpreters are expected to play, and which roles they themselves think they should play in any given setting. Gentile et al. (1996: 31) distinguish two role perceptions. One is how the interpreter perceives his/her own role and task, the other is how society and the general public view the role of the interpreter. Conference interpreters are viewed and regard themselves as detached and neutral, doing justice to all points of view in a balanced way but not contributing actively with comments of their own. This also finds its expression in the fact that they are separate from delegates in booths or even, in the case of remote interpreting, in another place. The views of interpreters themselves and of their clients as to what the interpreting task involves are generally rather similar. In most other settings, however, there is no such agreement on the role of the interpreter. As mentioned above, legal experts in many countries want the interpreter to act like a machine and render literal translations, whereas the medical expert may prefer either a committed or a detached interpreter. The standards published by the California Healthcare Interpreters Association (CHIA 2002) discuss the role of the medical interpreter as a patient advocate together with possible ways of acting to solve problems that may arise when patient autonomy and 
interpreter impartiality are in conflict. In settings where power relations are asymmetrical, an interpreter may tend to regard his/her role as that of a helper of the weaker side (Anderson 1978: 219). Zimman goes even further and warns that " $[\ldots]$ unqualified interpreters tend to get overinvolved, overidentified with the client, particularly if the client comes from the same culture" (1994: 128f). We have seen in section 3.1 which different approaches exist with regard to the question of impartiality. On the other hand, an interpreter may be tempted to regard him/herself as the assistant of the recruiting side, hoping that this raises his/her chances to be recruited again. Interpreters who lack professional qualifications but are sometimes recruited even as court interpreters tend to play down their role and responsibility; they ignore that they should render everything and remain impartial (Marzocchi 2005: 93f). Trained professional interpreters, on the other hand, are aware of the constraints on their role and heed the norms of completeness, accuracy and faithfulness as much as circumstances allow.

So obviously, the discussion about the role of an interpreter focuses on the 'conduit' approach (machine-like transfer of words) on the one hand and the interpreter as an active participant acting as a cultural mediator on the other. In my opinion, these two approaches do not constitute separate concepts between which one has to choose; in any communication situation there will be at least some degree of mediation by the interpreter (cf. Kalina 2011). In the conference setting, this may take the form of explanations of cultural peculiarities that do not exist in the target culture and therefore have no linguistic correspondence. In medical settings, the professional conduct of the interpreter is particularly crucial in his/her effort to be accepted as trustworthy by both parties involved; on the other hand, the interpreter may face extremely heterogeneous expectations even from within one group. Some medical experts expect the interpreter to explain in common language what the expert wishes to convey and to offer additional explanations regarding the patient's behaviour and sensitivities. Others may consider such behaviour as intrusive and do not want the interpreter to detract the patient's attention from their own medical expertise and sensitivity. In such situations, interpreters have to be able to assess which way of acting optimally suits both parties involved. An interpreter may alter the expert's register to make a patient understand what the doctor means, and may even transmit his/her own feelings of sympathy towards the patient. In some types of medical encounter, such as speech therapy, the interpreter is even granted a degree of semantic autonomy (Merlini \& Favaron 2005: 294) and is highly involved. 
[...] strict adherence to a dry, formal, passive and detached interpreting style, though it might be in line with an idealised notion of professional conduct, is not always the best way to serve one's clients [...] (Merlini \& Favaron 2005: 296).

In a legal setting, the representatives of the powerful side should admit that concepts which are unknown in the culture of a client must be explained to that client. Most importantly, it should always be clear what is part of the utterance by the source text speaker and what is a comment or explanation or expression of feeling voiced by the interpreter. To be able to act in full awareness of these challenges, an interpreter must be properly trained, highly qualified and rely on codes which offer guidelines for their informed decisions. Identifying possible and unacceptable roles or role expectations must therefore be part of interpreter curricula so that the role an interpreter assumes can be adapted to the setting according to its requirements.

\section{Conclusion: Best practice}

Interpreters' codes of ethics and interpreting quality find their common denominator in the concept of best practice. In quality evaluation, more attention should be paid to ethical questions. Quite a few interpreting decisions may well be explained in terms of ethical behaviour, so that the skills of an interpreter should not only be seen from the perspective of "text processing skills" but as "managing the dynamics of interpersonal interaction including issues of culture and unequal status and the interpreter's fraught position 'in between'” (Pöchhacker 2009: 137). 'Code of good practice' should include all that is required to perform quality assurance of professional interpreting, and 'code of conduct' should refer to all processes including those that are not directly related to interpreter output, i.e. serving the public interest and the client/user, and acting in the interest of the profession as an expert and practitioner of the highest professional level. This also includes the concept of 'professional dignity'.

Information about the fact that interpreters abide by codes of ethics and thus prove their commitment to best practice is not as widely spread among clients and users as it should be. Interpreter associations for the different profiles should therefore step up their efforts to spread such information. Professional codes are an important instrument for the profession to help raise the trust of the general public. So far, the majority of codes set up by professional associations addresses conference and court interpreting, where accuracy, completeness, impartiality, confidentiality are the main requirements (Hale 2008: 101). In healthcare interpreting, a number of codes have been set up, some by 
professional associations, some by institutions or supervisory authorities. The efforts undertaken recently by a working party under ISO TC 37 are geared at producing a standard for evaluating the services of community interpreters and have led to a draft standard of practice which contains, among eight ethical principles (accuracy and fidelity, confidentiality, impartiality, respect for persons, maintaining role boundaries, accountability, professionalism, continued competence, and transparency) also that of impartiality. It is to be hoped that the final version of this standard will make the necessary distinction as to where this principle has to be heeded and where it cannot be an absolute tenet. Only then will such a standard not only help recruiters of interpreters but also community interpreters themselves who need an instrument on which they can base their assessment of a specific setting.

Best practice in interpreting settings is based on a number of general rules aimed at achieving quality of the service that apply to virtually all interpreting settings. However, the choice of behaviour and action is very much determined by the requirements of a specific setting, and interpreters need to be aware of this. It would therefore be advisable to have codes of ethics for the different settings which spell out the specific ways of acting and choices to be made in that particular setting. Even though there will always be situations which are not covered by any code, such a tailored set of guidelines would help interpreters adapt to the requirements of any given setting. Such codes would also be a powerful instrument if agencies that often attempt to recruit at lowest cost are to be made to adhere to the rules of the profession.

Intercultural awareness on the part of the interpreter is an absolute requirement, and very special skills are needed to act in situations where such awareness is lacking on the part of the expert or client side who may otherwise fail to realise that they have not understood each other.

The conclusion is that ethics should form part and parcel of all types of interpreter training. This is to some extent reality but what is still lacking in many curricula is setting-specific training that focusses on such differences in behaviour as discussed above. Such specific training in conference interpreting has been offered for decades, whereas in many countries training for other settings is slow to follow, owing, among other things, to the fact that prestige and remuneration for such work are poor. However, communities and society as a whole should accept that such settings also require highly qualified interpreters and that their services need to be remunerated accordingly. It is a matter of ethics practised by a society whether intercultural comprehension and understanding is worth the contribution of qualified interpreters or not, and to understand that the costs for these will be far outweighed by the benefit to society. 


\section{References}

ANGELELli, Claudia V. (2004) Revisiting the Interpreter's Role. A study of conference, court, and medical interpreters in Canada, Mexico, and the United States. Amsterdam: John Benjamins.

ANDERSON, R. Bruce W. (1978) "Interpreter Roles and Interpretation Situations. Cross-Cutting Typologies." In: Gerver, David \& Henry W. Sinaiko (eds.) 1978. Language Interpretation and Communication. New York: Plenum Press, pp. 217-229.

ANDRES, Dörte. (2009) "Dolmetschen und Macht." In: Ahrens, Barbara; Monika Krein-Kühle; Lothar Černý \& Michael Schreiber (eds.) 2009. Translationswissenschaftliches Kolloquium I. Beiträge zur Übersetzungs- und Dolmetschwissenschaft. FASK - Publikationen des Fachbereichs Angewandte Sprach- und Kulturwissenschaft der Johannes Gutenberg-Universität Main in Germersheim. Frankfurt/Main: Peter Lang, pp. 123-143.

Apple, G.; Paula L. Hannaford \& G. Thomas Munsterman (eds.) (1997) Manual for Cooperation Between State and Federal Courts. Electronic version available at: <https://bulk.resource.org/courts.gov/fjc/stfedman.pdf>

BüHLER, Hildegund. (1986) "Linguistic (semantic) and extra-linguistic (pragmatic) criteria for the evaluation of conference interpretation and interpreters." Multilingua 5:4, pp. 231-235.

Chesterman, Andrew. (1993) "From 'Is' to 'Ought': Laws, Norms and Strategies in Translation Studies." Target 5:1, pp. 1-20.

Chesterman, Andrew. (2001) "Proposal for a Hieronymic Oath." The Translator 7:2, pp. 139-154.

DIRIKER, Ebru. (2001) De-/Re-Contextualising Simultaneous Interpreting: Interpreters in the Ivory Tower? Bebek/Istanbul: Bogazici University. Unpublished Ph.D. thesis.

DIRIKER, Ebru. (2004) De-/Re-Contextualizing Conference Interpreting. Amsterdam: John Benjamins.

Duflou, Veerle. (2007) "Norm research in Conference Interpreting: Some methodological aspects." In: Schmitt, Peter A. \& Heike E. Jüngst (eds.) 2007. Translationsqualität. Leipziger Studien zur angewandten Linguistik und Translatologie. Frankfurt am Main: Peter Lang, pp. 91-99.

Ellington, James W. (Translation). (1993) Imanuel Kant: Ethical Philosophy Grounding for the Metaphysics of Morals. 3rd ed. Indianapolis: Hackett

GARZONE, Giuliana. (2002) "Quality and norms in interpretation." In: Garzone, Giuliana \& Maurizio Viezzi (eds.) 2002. Interpreting in the 21st Century. Amsterdam: John Benjamins, pp. 107-119.

Gentile, Adolfo; Uldis Ozolins \& Mary Vasilakakos. (1996) Liaison interpreting. A Handbook. Melbourne: Melbourne University Press. 
GENTILE, Adolfo. (2012) "Interpreting as a human right - institutional responses: the Australian Refugee Review Tribunal." The Interpreters' Newsletter 17, pp. 157-172.

HALE, Sandra. (2007) Community Interpreting. Basingstoke: Palgrave Macmillan.

HALE, Sandra. (2008) "Controversies over the role of the court interpreter." In: Valero Garcés, Carmen \& Anne Martin (eds.) 2008. Crossing Borders in Community Interpreting. Amsterdam: John Benjamins, pp. 99-121.

HeBEnSTREIT, Gernot. (2010) "Berufskodizes als Konstituenten einer Translationsethik? Versuch einer Modellierung." In: Grbić, Nadja; Gernot Hebenstreit; Gisella Vorderobermeiner \& Michaela Wolf (eds.) 2010. Translationskultur revisited. Festschrift für Erich Prunč. Tübingen: Stauffenburg, pp. 281-295.

HewITT, William E. (1995) Court Interpretation: Model Guides for Policy and Practice in the State Courts. National Center for State Courts.

HozA, Jack. (2003) "Toward an Interpreter Sensibility: Three Levels of Ethical Analysis and a Comprehensive Model of Ethical Decision-making for Interpreters." Journal of Interpretation 2003, pp.1-48.

KADRIC, Mira. (2001). Dolmetschen bei Gericht. Erwartungen, Anforderungen, Kompetenzen. Wien: WUV.

KALINA, Sylvia. (2011) "Dolmetschwissenschaft auf interkulturellen Pfaden." In: Bauer, Matthias; Rüdiger Pfeiffer-Rupp; Claudia Sasse \& Ursula Wienen (eds.) Sprache, Literatur, Kultur: Translatio delectat. Festschrift für Lothar Cerny zum 65. Geburtstag. Münster: LIT, pp. 211-231.

Ko, Leong. (2006) "Fine-Tuning the Code of Ethics for Interpreters and Translator." Translation Watch Quarterly 2:3, pp. 45-47.

LOTRIET, Annelie. (2000) "Interpreter Training in South Africa: The Challenges." In: Kalina, Sylvia; Silke Buhl \& Heidrun Gerzymisch-Arbogast (eds.) (2000). Dolmetschen: Theorie. Praxis. Didaktik. St. Ingbert: Röhrig Universitätsverlag, pp. 261-271.

MARZOCCHI, Carlo. (2005) "On norms and ethics in the discourse on interpreting." The Interpreters' Newsletter 13, pp. 87-107.

MERLINI, Raffaela \& Roberta Favaron. (2009) "Quality in healthcare interpreter training - Working with norms through recorded interaction." In: Hale, Sandra; Uldis Ozolins \& Ludmila Stern (eds.) 2009. Quality in interpreting - a shared responsibility. The Critical Link 5 Conference, Sydney, 11-15/04/2007. Amsterdam/Philadelphia: Benjamins, pp. 187-200.

MikKELSON, Holly. (1998) "Towards a redefinition of the Role of the Court interpreter." Interpreting 3:1, pp. 21-45. Electronic version available at: <http:// www.acebo.com/papers/pmenu.htm>.

MORRIS, Ruth. (1999) "The Gum Syndrome: Predicaments in Court interpreting." Forensic Linguistics 6:1, pp. 6-29. Electronic version available at: <http://www. 
ruth-morris.info/wp-content/uploads/2010/03/GumForensicLinguistics. pdf>.

NisKA, Helge. (1995) "Just Interpreting: Role Conflicts and Discourse Types in Court Interpreting." In: Morris, Marshall (ed.) 1995. Translation and the Law. Amsterdam: John Benjamins, pp. 293-316.

PÖCHHACKER, Franz. (2009) "Issues in Interpreting Studies." In: Munday, Jeremy (ed.) 2009. The Routledge Companion to Translation Studies. London: Routledge, pp. 128-140.

PÖCHHACKER, Franz \& Miriam Shlesinger. (eds.) (2007) Healthcare Interpreting. Discourse and Interaction. Amsterdam: John Benjamins.

PRUNČ, Erich. (2007) Entwicklungslinien der Translationswissenschaft. Von den Asymmetrien der Sprachen zu den Asymmetrien der Macht. Berlin: Frank \& Timme.

PRUNČ, Erich. (2012) "Rights, realities and responsibilities in community interpreting." The Interpreters' Newsletter 17, pp.1-12.

RudVIN, Mette. (2007) "Professionalism and ethics in community interpreting. The impact of individualist versus collective group identity." Interpreting 9:1, pp. 47-69.

SCHÄFFnER, Christina (ed.) (1999) Translation and Norms. Clevedon: Multilingual Matters.

SCHWEDA Nicholson, Nancy. (1994) "Professional Ethics for Court and Community Interpreters." In: Hammond, Deanna L. (ed.) 1994. Professional Issues for Translators and Interpreters. Amsterdam: John Benjamins, pp. 79-98.

SELESKOVITCH, Danica. (1986) "Who should assess an interpreter's performance? - Comment on Hildegund Bühler." Multilingua 5, p. 236.

Several Authors (AIIC). (2012) Code of Professional Ethics. Electronic version available at: <http://aiic.net/code-of-ethics>

Several Authors (AUSIT). (2012) Code of Ethics and Code of Conduct. Electronic version available at: <http://ausit.org/AUSIT/About/Ethics__Conduct/Code_ of_Ethics/AUSIT/About/Code_of_Ethics.aspx>

SEVERAL AUthORS (CHIA - California Healthcare Interpreters Association). (2002) California Standards for Healthcare Interpreters. Ethical Principles, Protocols, and Guidance on Roles \& Intervention. Electronic version available at: <http://www.chia.ws/standards.htm>

SeVeral Authors (ImPLI - Improving Police and Legal Interpreting). (2012) Final Report. Electronic version available at: <http://www.isit-paris.fr/documents/ImPLI/Final_Report.pdf>

SEVERAL AuthORS (ISO/DIS 13611). (in press) Interpreting - Guidelines for community interpreting (more information: <http://www.iso.org/iso/catalogue_ detail.htm? csnumber $=54082>$ ). 
SEVERAL AUthors (ITI - Institute of Translation and Interpreting). (2013) Code of professional conduct. Electronic version available at: <http://www.iti.org.uk/ attachments/article/154/Code\%20of\%20Conduct\%20-\%20individual.pdf>

SEVEral Authors (ITIA - Irish Translators' and Interpreters' Association). (2009) Code of Ethics for Community Interpreters. Electronic version available at: <http://www.fit-europe.org/vault/ITIA_code_interpreters.pdf>

SEVERAL Authors (NAATI - National Accreditation Authority For Translators And Interpreters). (2013) Ethics of Interpreting and Translating. A Guide to Obtaining NAATI Credentials. Electronic version available at: http://www. naati.com.au/PDF/Booklets/Ethics_Booklet.pdf>

SEVERAL AUTHORS (RID - Registry of Interpreters fort the Deaf). (2005) NAD RID Code of Professional Conduct. Alexandria: Registry of Interpreters for the Deaf. SHLESINGER, Miriam. (1989) "Extending the Theory of Translation to Interpretation: Norms as a Case in Point." Target 1, pp. 111-115.

SHLESINGER, Miriam. (1999) "Norms, strategies and Constraints: How do we tell them apart?.” In: Álvarez Lugrís, Alberto \& Anxo Fernández Ocampo (eds.) 1999. Anovar/Anosar Estudios de traducción e interpretación (Vol. I). Vigo: Universidade de Vigo, pp. 65-77.

Stenzl, Catherine. (1989) "From Theory to Practice and from Practice to Theory." In: Gran, Laura \& John Dodds (eds.) 1989. The Theoretical and Practical Aspects of Teaching Conference Interpretation. Proceedings of the Trieste Symposium, 1986. SSLM. Udine: Campanotto, pp. 23-26.

TOURY, Gideon. (1980) In search of a theory of translation. Tel Aviv: The Porter Institute for Poetics and Semiotics.

WitTGENSTEIN, Ludwig. (1929) Lecture on Ethics. Electronic version available at: <http://www.galilean-library.org/manuscript.php?postid=43866>

ZIMMAN, Leonor. (1994) "Intervention as a pedagogical problem in community interpreting." In: Dollerup, Cay \& Anne Lindegaard (eds.) 1994. Teaching Translation and Interpreting: Insights, Aims, Visions. Selected papers from the Second 'Language International' Conference, Elsinore, Denmark, 4-6 June 1993. Amsterdam: John Benjamins, pp. 217-224. 


\section{BIONOTE / NOTA BIOGRÁFICA}

SYLVIA KALINA has a Diploma in Conference Interpreting (1970) from Institute for Translation and Interpreting, Heidelberg University with German A, English B and French C. Employment with EU (then EEC) Conference Interpreting Service, later free-lance conference interpreter, working mainly on the German market with German, English and French. From 1980: Full teaching assignment with Heidelberg University, Institute for Translation and Interpreting. 1997: Dr. phil. (Linguistics and Translation), with dissertation on strategic processes in interpreting, published in 1998. Appointed Professor for the Theory and Practice of Interpreting at Cologne University of Applied Sciences, Institute for Translation and Multilingual Communication as from September 1999. Current research focus: Processes and strategies in interpreting, interpreting quality, training methodology. Member of AIIC (Association Internationale des Interprètes de Conférence), now as Associate Member, GAL (German Association of Lingusitics), DGÜD (German Society for Translation Studies), EST (European Society for Translation Studies), BDÜ (Bundesverband der Übersetzer aund Dolmetscher), German-British Society, Transforum Deutschland. Retired as from September 2012, with continuing teaching assignments at Heidelberg University and Cologne University of Applied Sciences.

SYLVIA Kalina Diplomdolmetscherin, Dr. phil., (Promotion Universität Heidelberg 1997 zum Thema „Strategische Prozesse beim Dolmetschen“), 1980-1999 Dozentin für Konferenzdolmetschen am Institut für Übersetzen und Dolmetschen der Universität Heidelberg; daneben freiberufliche konferenzdolmetschpraktische Tätigkeit. 1999 Berufung als Professorin an die FH Köln (Mehrsprachige Kommunikation mit Schwerpunkt Translation). Forschungsschwerpunkte: Strategien beim Dolmetschen, Dolmetschqualität, Didaktik des Dolmetschens. Mitgliedschaften: AIIC (Association Internationale des Interprètes de Conférence), inzwischen assoziiert, GAL (Gesellschaft für Angewandte Linguistik), DGÜD (Deutsche Gesellschaft für Übersetzungsund Dolmetschwissenschaft), EST (European Society for Translation Studies), BDÜ (Bundesverband der Übersetzer aund Dolmetscher), DeutschBritische Gesellschaft, Transforum Deutschland. Emeritierung September 2012. Derzeit Lehraufträge an der FH Köln und der Universität Heidelberg (Dolmetschwissenschaft). 